\title{
THE $\alpha$ FOLATE RECEPTOR IS HIGHLY ACTIVATED IN MALIGNANT PLEURAL MESOTHELIOMA
}

Raphael Bueno, MDa

Krishnarao Appasani, $\mathrm{PhD}^{\mathrm{a}}$

Harriet Mercer, BS ${ }^{\mathrm{a}}$

Susan Lester, $\mathrm{MD}, \mathrm{PhD}^{\mathrm{b}}$

David Sugarbaker, $\mathrm{MD}^{\mathrm{a}}$
Objective: To determine whether the folate receptor gene is overexpressed in malignant pleural mesothelioma.

Methods: Differential display analysis was performed with fresh frozen RNA obtained from normal lung, pleura, and mesothelioma. Sixty differentially expressed genes were identified and characterized. One gene that was overexpressed in mesothelioma versus normal tissue was the human $\alpha$ folate receptor. In situ hybridization with antisense probes designed on the basis of the sequence of the folate receptor was performed with frozen sections from 61 patients (33 epithelial and 28 mixed or sarcomatoid tumors) with malignant pleural mesothelioma. The controls included normal pleura, normal lung, other cancers, and sense controls for all of the tumors. Northern analysis with a folate receptor probe and immunohistochemical analysis with anti$\alpha$ folate receptor antibodies were also performed.

Results: Forty-four (72\%) of the 61 mesothelioma tumors were found to have between 2-fold and 4-fold higher mRNA expression of the folate receptor when compared with the control tissues. The histologic type of the tumor did not affect the rate of folate receptor activation. Northern analysis and immunohistochemical experiments confirmed these findings.

Conclusions: A majority of mesothelioma tumors examined overexpress the $\alpha$ folate receptor protein when compared with normal adjacent tissues. This finding may help explain the observations that antifolate drugs have activity in the treatment of mesothelioma. It also encourages further study of folate receptor-related treatment strategies in this malignancy. ( $\mathrm{J}$ Thorac Cardiovasc Surg 2001;121:225-33)
$\mathrm{M}$ alignant pleural mesothelioma is a rare and fatal malignancy of the pleura usually resulting from asbestos exposure and accounting for 2500 new cases in the United States every year. ${ }^{1}$ The incidence of this dis-

From the Division of Thoracic Surgery ${ }^{\mathrm{a}}$ and the Department of Pathology, ${ }^{\mathrm{b}}$ Brigham and Women's Hospital, Harvard Medical School, Boston, Mass.

This work was partially funded by The Vancouver Foundation and the Brigham Surgical Group Foundation.

Read at the Eightieth Annual Meeting of The American Association for Thoracic Surgery, Toronto, Ontario, Canada, April 30-May 3, 2000.

Received for publication May 4, 2000; revisions requested June 12, 2000; revisions received Aug 9, 2000; accepted for publication Aug 25, 2000.

Address for reprints: Raphael Bueno, MD, Division of Thoracic Surgery, Brigham and Women's Hospital, 75 Francis St, Boston, MA 02115.

Copyright @ 2001 by The American Association for Thoracic Surgery

$0022-5223 / 2001 \$ 35.00+0 \quad \mathbf{1 2 / 6 / 1 1 1 1 7 6}$

doi:10.1067/mtc.2001.111176 ease has been steadily rising for the past 10 years and is projected to continue to increase in the upcoming decade worldwide. The molecular events that ultimately result in mesothelioma are not understood, nor have any tumor markers been identified in this disease. ${ }^{2,3}$

Until recently, no effective treatments have been available for mesothelioma. Clinical trials have documented a response rate in the $20 \%$ range for most chemotherapeutic agents with activity, and the majority of patients have been treated with palliative and supportive measures. With this treatment, the median survival ranged from 4 to 12 months., ${ }^{2,4}$ In the past decade, a few advances have been made in the treatment of mesothelioma. Extrapleural pneumonectomy followed by adjuvant chemoradiation has been shown effective in both palliation and prolongation of survival in selected patients with mesothelioma. ${ }^{6,7}$ Furthermore, new chemotherapeutic agents have shown a high response rate for mesothelioma in preliminary studies. ${ }^{8,9}$ Despite the improved surgical and multimodality 
options for the treatment of malignant pleural mesothelioma, the majority of patients will eventually die of their disease. Most patients who undergo extrapleural pneumonectomy will eventually have a local recurrence or, as they survive longer, metastatic spread. ${ }^{1,10}$ Additional modalities are required to achieve better control of the disease both locally and systemically. With that goal in mind, we have concentrated our efforts on identifying how RNA expression in mesothelioma tumor cells differs from that of the tissues in which it arises, lung and pleura. We have performed screening differential display experiments that have identified the folate receptor gene as overexpressed in a single patient with mesothelioma. In this article, we evaluate the folate receptor gene expression pattern in mesothelioma tumors.

\section{Materials and methods}

Tissues and clinical database. Frozen tumor and normal tissue specimens were obtained from the Thoracic Oncology Tumor Bank at the Brigham and Women's Hospital. Surgical specimens obtained from patients undergoing extrapleural pneumonectomy or pleurectomy were divided into small samples $(3 \times 3 \times 3 \mathrm{~mm})$, snap frozen, and stored at $-140^{\circ} \mathrm{C}$. Normal tissues from patients with mesothelioma and tissues from patients without mesothelioma were also collected, similarly processed, and preserved in the tumor bank. At least one sample adjacent to each snap-frozen sample was embedded in optimal cutting temperature medium (OCT) for histologic sectioning to estimate tumor cell content of the snapfrozen sample and to provide sections for in situ hybridization and immunohistochemistry. Slides stained with hematoxylin and eosin were generated from OCT blocks of about 200 mesothelioma tissues in the tumor bank and reviewed by a pathologist to identify those tumor samples that had greater than 50\% tumor cells among nucleated cells on the slide. Eighty such tumor samples were identified, most with adjacent control normal tissues (lung, pleura, or skeletal muscle). The adjacent snap-frozen samples were selected for further study. Relevant clinical data were collected for all 80 patients and linked to both the specimens and the patient identifier link-ups (destroyed by the Tumor Bank staff before distribution of the tissue to this project to protect patient confidentiality). Tissue collection and these experiments were performed in accordance with and with the approval of the institution's research review board. The tissues generated as described above with their linked clinical information were used in the experiments presented in this report.

Differential display analysis. Normal lung, normal pleura, and mesothelioma tumor tissues were used in the experiment. The tissues were homogenized, and RNA was isolated with a Qiagen extraction kit (Qiagen, Inc, Chatsworth, Calif). Differential display polymerase chain reaction (PCR) analysis was performed as described by Liang and Pardee..$^{11,12}$ Sixty bands were selected that were differentially expressed in the three tissues used above. These bands were then cut out and purified by means of the QIAquick Gel Extraction Kit (Qiagen, Inc). The purified bands were then re-amplified by PCR and subcloned into the pCR-TRAP cloning vector (GenHunter Corporation, Nashville, Tenn). All inserts were then subjected to double-strand DNA sequencing by means of the ABI PRISM automatic sequencer (Applied Biosystems, Foster City, Calif). The DNA sequences were analyzed against the Gene Bank via a Blast search (http://www.ncbi.nlm.nih.gov).

In vitro RNA probe synthesis and fluorescent in situ hybridization. Frozen sections $6 \mu \mathrm{m}$ thin were prepared from OCT tissue blocks on a Minotome cryostat (Damon/IEC Division, Needham Heights, Mass) and stored at $-80^{\circ} \mathrm{C}$ until use. Samples were fixed in $4 \%$ paraformaldehyde for 20 hours and then treated in $30 \%$ sucrose for 16 hours at $4{ }^{\circ} \mathrm{C}$. The entire 320 base pair (bp) sequence of the $\alpha$ folate receptor gene fragment (tag \#37) was transcribed with T7 and SP6 to generate both antisense and sense RNAs, respectively. The in vitro transcription was performed with 50 ng complementary DNA, fluorescein-12-uridine-5'-triphosphate, and either with SP6 or T7 RNA polymerase as described by the manufacturer (Roche Molecular Biochemicals, Indianapolis, Ind). Subsequent manipulations were performed, and the labeled nucleotides were separated from the unlabeled on a Sephadex G-50 column (GeneExpression Systems, Inc, Waltham, Mass). Labeled RNA was collected from these columns into an RNAse-free tube, precipitated, and finally resuspended in $50 \mu \mathrm{L}$ of $0.1 \mathrm{~mol} / \mathrm{L}$ dithiothreitol. The concentration of RNA was measured by spectrophotometer at $260 \mathrm{~nm}$, and the concentration of fluorescein label was determined at $495 \mathrm{~nm}$. The processed tissue sections were rehydrated in $70 \%$ ethanol for 10 minutes. The slides were incubated in DNAse-free RNAse $(100 \mu \mathrm{g} / \mathrm{mL}$ in $2 \times$ standard sodium chloride citrate) for 1 hour at $37^{\circ} \mathrm{C}$ followed by treatment with $0.2 \mathrm{~mol} / \mathrm{L} \mathrm{HCl}$ for 20 minutes. In situ hybridization was performed with a Uni-in-situGeneLock Kit (GeneExpression Systems, Inc). Normal pleura and mesothelioma tissue sections were hybridized with 10 ng denatured labeled RNA probe at $37^{\circ} \mathrm{C}$ for 15 hours before performance of pre-hybridization at $37^{\circ} \mathrm{C}$ for 2 hours. At the end of the hybridization, the probe was removed, and the slides were washed under high stringent conditions. Finally, a drop of Slow-fade reagent (Molecular Probes Inc, Eugene, Ore) was added to the samples, which were then sealed with nail polish and kept in the dark at $4^{\circ} \mathrm{C}$ until analyzed with the Bio-Rad MRC 1024 laser based confocal microscope (BioRad Laboratories, Hercules, Calif). The resulting slides were scored from 1 to 5 on the basis of the expression. This analysis was performed for 61 different mesothelioma tissues, as well as for three samples of normal pleura. Normal lung controls samples, samples from our tumor bank, and several control tumor tissues that were purchased (Novagen, Madison, Wis) were also analyzed.

Northern blot analysis. Total RNA $(20 \mu \mathrm{g})$ was fractionated in $2.2 \mathrm{~mol} / \mathrm{L}$ formaldehyde $/ 1.2 \%$ agarose gels, transferred to Nytran membrane (Schleicher \& Schuell, Dassel, 
AAGCTTAACGAGGAAGTGGCGAGGTTCTATGCTGCACCCATGCATGTGAATG CTGGTGAGATGCTTCATGGGACTGGGGGTCTCCTGCTCAGTCTGGCCCTGATG CTGCAACTCTGGCTCCTTGGCTGAGTTCAGTCCTCCCAAACTACCTGCCCTCA GCTTGGATAACCAGGCTGGGCTCAACTCAGCTCCCACAAATGACAGCCCCTT AAGCATGCTTCTATTAGTCACCTATCCCTCTGTCACCCACTCTTGTTGCTGCTC CATGGTGGGGCCAAGATCACTTCTAATAAACAGAGTGTTTCTAATAAAAAAA A AAA-3'

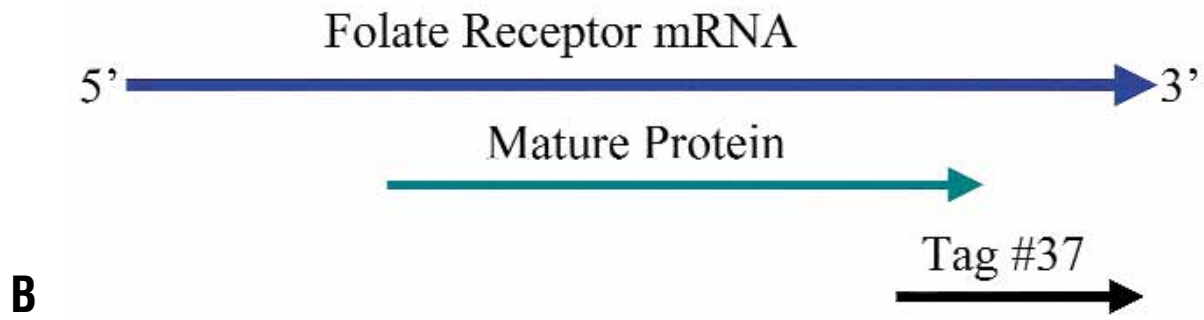

Fig 1. The nucleotide sequence of tag \#37 (A) and the representation of the sequence of the $\alpha$ folate receptor full length mRNA transcript, its coding region, and sequence tag \#37 (B).

Germany), and hybridized as previously described. ${ }^{13}$ Hybridizations were carried out by means of the tag \#37 probe, a 0.32-kilobase (kb) fragment obtained by PCR amplification from the plasmid pKA37 followed by band extraction and gel purification with Qiagen gel extraction kit (Qiagen, Inc, US, Valencia, Calif). Human $\beta$ actin cDNA probe was prepared with the use of Human Gene Detect Kit I (GeneExpression Systems, Inc) and used as a control. High specific probes were generated by labeling cDNA fragments with $\alpha-\left[{ }^{32} \mathrm{P}\right]$ deoxycytidine triphosphate $(6000 \mathrm{Ci} / \mathrm{mmol})$, using a random prime labeling kit (NEN/Dupont, Boston, Mass) and hybridized as described. ${ }^{10}$ Messenger RNA transcript expression levels were quantitated by exposing the probed filter to x-ray film in a Molecular Devices cassette and further analyzed in a phosphorImager (Molecular Dynamics, Inc, Sunnyvale, Calif).

Immunohistochemical analysis. Frozen sections $6 \mu \mathrm{m}$ thick were cut with a Minotome cryostat, fixed in acetone at $4^{\circ} \mathrm{C}$ for 10 minutes, and stored at $-20^{\circ} \mathrm{C}$ until use. Before use, they were brought to room temperature and washed with phosphate-buffered saline solution (PBS) three times. The slides were incubated in $0.3 \%$ hydrogen peroxide, which was prepared in PBS for 10 minutes, to quench endogenous peroxidase activity. Two different monoclonal antibodies against the $\alpha$ folate receptor, Mov18 and Mov19 (gifts of Dr S. Canevari, National Tumor Institute, Milan, Italy), were used as described by Mantovani and associates. ${ }^{14}$ Immuno- histochemistry was performed with a Uni-Histochem kit (GeneExpression Systems, Inc), and the slides were mounted with coverslips, analyzed through a Carl Zeiss microscope (Carl Zeiss, Inc, Thornwood, NY), and photographed. Slides stained with trp E antibody (Oncogene Research Products, Cambridge, Mass) to monitor the background staining were used as controls. Sections of human fallopian tube adenocarcinomas, lung adenocarcinomas, uterine carcinomas, squamous cell carcinomas, and normal lung and pleura were used as positive and negative controls. The cells that immunoreacted with the respective antibodies were counted, as were the total tumor cells per slide, and percentages of folate receptor expression were obtained.

\section{Results}

Differential display analyses comparing RNA expression in fresh frozen tissues obtained from mesothelioma, normal lung, and pleura was performed. The mesothelioma tissue was obtained from a single patient with epithelial subtype. Sixty differentially expressed cDNA tags were selected for further analysis. One of the $60 \mathrm{cDNA}$ tags obtained from the differential display experiments, cDNA tag \#37, was highly expressed in mesothelioma only and was also noted to have a $92 \%$ homology to the human $\alpha$ folate receptor 


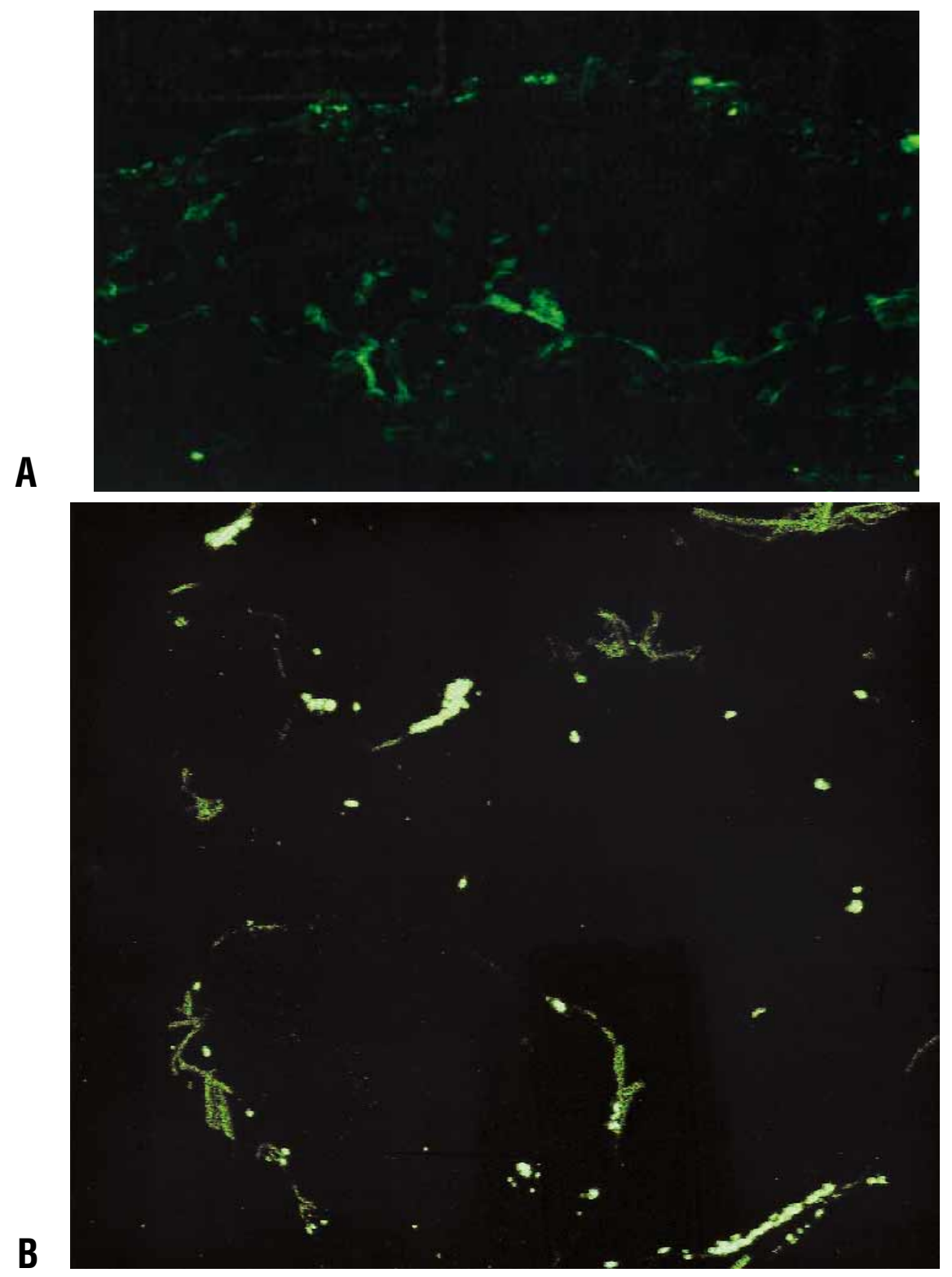

Fig 2. Fluorescent in situ hybridization with an antisense probe generated on the basis of the sequence of tag \#37 of normal pleura (A) and normal lung (B).

cDNA. ${ }^{15}$ Complementary DNA tag \#37 covers the entire $3^{\prime}$ untranslated region, as well as $117 \mathrm{bp}$ of coding region in the $3^{\prime}$ region of the 1230-bp long cDNA of the human $\alpha$ folate receptor. The cDNA tag is $320 \mathrm{bp}$ long and has a sequence nearly identical to that of the $\alpha$ folate receptor transcript from base pair 907 to 1230 . The homology was $100 \%$ in the protein-coding region from base pair 907 of the $\alpha$ folate receptor cDNA, where the cDNA tag sequence commences, to base pair 1024, where the translation ends (Fig 1). Our differen- tial display analysis suggests that the human $\alpha$ folate receptor gene is represented by cDNA tag \#37 and is significantly more expressed in mesothelioma than in adjacent normal lung or pleura.

Fluorescence in situ hybridization was used to determine the expression of cDNA tag \#37 in mesothelioma. Sixty-one different mesothelioma tissues (33 epithelial, 25 mixed, and 3 sarcomatoid) were used, as well as a number of other tissues including 3 normal lung, 3 normal pleura, uterine carcinoma, fallopian tube adenocar- 


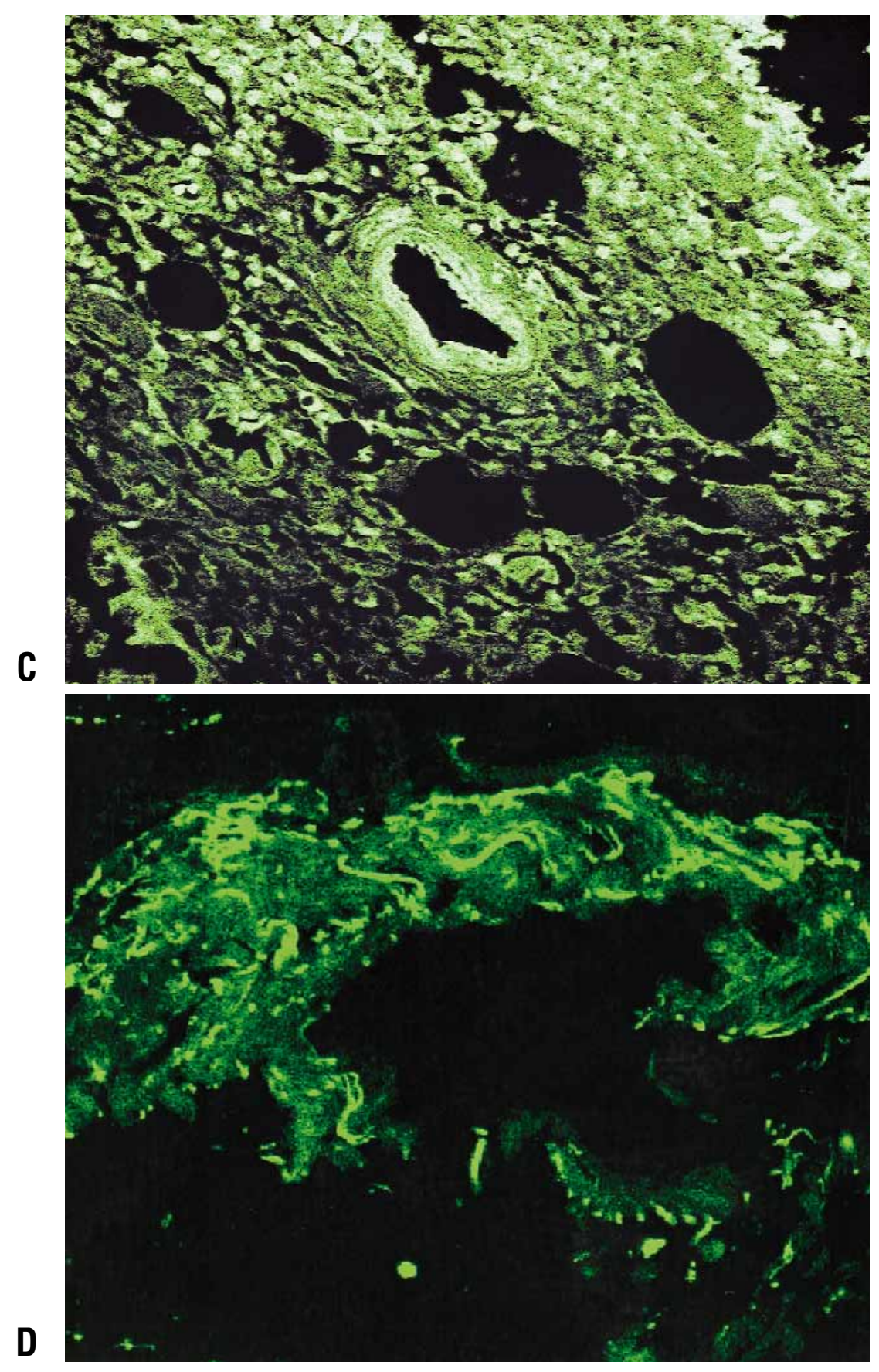

Fig 2. Cont'd. Fallopian tube adenocarcinoma (C) and malignant pleural mesothelioma (D).

cinoma, breast carcinoma, and renal cell carcinoma. Each tumor sample was tested twice with both a normal pleura and normal lung specimen on the same slide. All of the slides were scored by same observer using a scale of 1 to 5 ( $1=$ minimal hybridization; $5=$ maximal hybridization). The pulmonary tissue controls gave a score of 1 or 2 , consistent with minimal baseline expression of the $\alpha$ folate receptor in lung and pleura (Fig 2, $A$ and $B$ ). Most normal human tissues analyzed had low levels of expression, as previously reported. ${ }^{16}$ Uterine cancer and human breast cancer had low levels (scored 1 to 2), and fallopian tube adenocarcinoma (Fig $2, C$ ) had a high level (scored 4) of expression as previously reported. ${ }^{16,17}$ Forty-four $(72 \%)$ of the mesothe- 


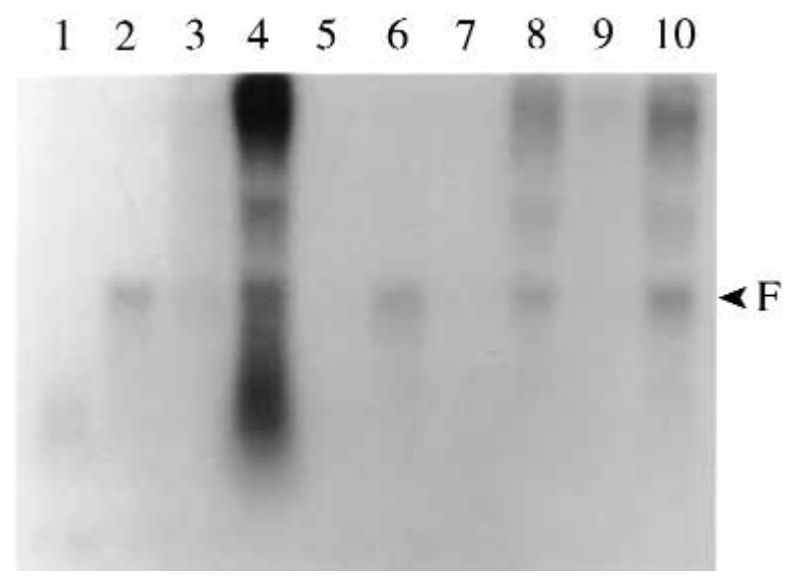

Fig 3. Northern blot demonstrating the presence of a $1.3-\mathrm{kb}$ band (marked $F$ on the blot) in tumor samples and nearly no band in the adjacent normal controls. Columns 1 through 10 show alternating adjacent normal tissue and mesothelioma tissue from 5 separate patients.

lioma tissues were scored between 3 and 5 (Fig 2,D), and the rest scored 1 to 2 . To determine whether the histologic subtype of mesothelioma affected the expression level of the $\alpha$ folate receptor RNA, we used the Student $t$ test to analyze the hybridization score in the mixed histology subgroup versus the epithelial histology subgroup. We found no statistical difference between the two subgroups (2-sample $t$ [degrees of freedom] $=0.2468, P=.8059$ ). We also performed a Kaplan-Meier cumulative survival analysis and found no survival difference between the group that had elevated folate receptor levels and the group that did not. We conclude that the $\alpha$ folate receptor transcript is activated in a majority of mesothelioma tissues tested and independently of histologic subtype.

We selected five of the mesotheliomas to perform Northern analysis, three from specimens that had low activity in the in situ hybridization experiments and two that had elevated expression of the folate receptor. We compared equal amounts of total RNA from these tumors and their normal controls using the tag \#37 sequence as a probe. There are 10 lanes in the Northern blot, which are arranged as sequential adjacent normal and tumor columns. As can be seen in Fig 3, the normal controls have a barely recognizable band, whereas the tumors all have a band approximately $1.3 \mathrm{~kb}$ in size, which is the expected size of the $\alpha$ folate receptor transcript. ${ }^{15}$ The second lane and the seventh lane represent tumor specimens that were overexpressed in the in situ experiments. The Northern blot analysis, which is more sensitive than the in situ experiments, supports the con- clusion that the $\alpha$ folate receptor transcript is expressed in elevated levels in mesothelioma relative to adjacent normal controls, even in some tissues that do not have very high expression in the in situ experiments.

Finally, we obtained two anti- $\alpha$ folate receptor monoclonal antibodies ${ }^{14,18}$ and used them to immunolocalize the folate receptor on frozen mesothelioma tissues, as well as in appropriate control tissues. Specimens obtained from normal pleura, normal lung, uterine carcinoma, and squamous carcinoma of the lung served as negative controls. Specimens from fallopian tube carcinoma and lung adenocarcinoma served as positive controls. ${ }^{19}$ We have used 17 mesothelioma specimens that were also used in the in situ experiments. As seen in Fig $4, A$, there is none to minimal expression of the receptor in normal pleural cells, but 13 of the mesothelioma tumor samples demonstrated immunolocalization at the cell membrane at moderate to high levels (Fig 4, B). In 15 of the 17 specimens there was complete correlation of expression between the in situ and the immunohistochemical experiments. We conclude that the $\alpha$ folate receptor gene and protein are expressed in a majority of the mesothelioma tumors that we examined at higher levels than in adjacent normal tissues.

\section{Discussion}

The $\alpha$ folate receptor is a glycoprotein that is anchored to the cell membrane of a variety of epithelial cells. It binds folate at a high affinity and mediates its transmembrane transport into the cytoplasm for use in purine and pyrimidine biosynthesis. ${ }^{15-17,20}$ The $\alpha$ folate receptor has been shown to be highly expressed in a number of tumors, most significantly in ovarian carcinoma and mesodermally derived tumor, where it has recently been exploited for novel therapies. ${ }^{16,17,21}$ It is also reported to be highly expressed in nasopharyngeal carcinoma and cervical carcinoma. Franklin and colleagues ${ }^{19}$ performed immunohistochemical analysis on lung cancer and demonstrated that adenocarcinomas, but not squamous cell carcinomas, express the folate receptor intensely. Additional studies reveal that this receptor is not highly expressed in lung tissues, but that it is present in type I and II pneumocytes. ${ }^{17}$ Although the $\alpha$ folate receptor is not the only mediator for folate and antifolate drug transport into the cytoplasm of tumor cells, it can function as the major folate transport system when expressed at high levels. ${ }^{17,20}$ The $\alpha$ folate receptor gene and the other related folate receptor genes $\beta$ and $\chi$ are closely related and located on chromosome $11 .{ }^{17}$ The $\alpha$ folate receptor transcript is 1230 bp long, and the mature protein contains 239 amino acid residues. ${ }^{15}$ 

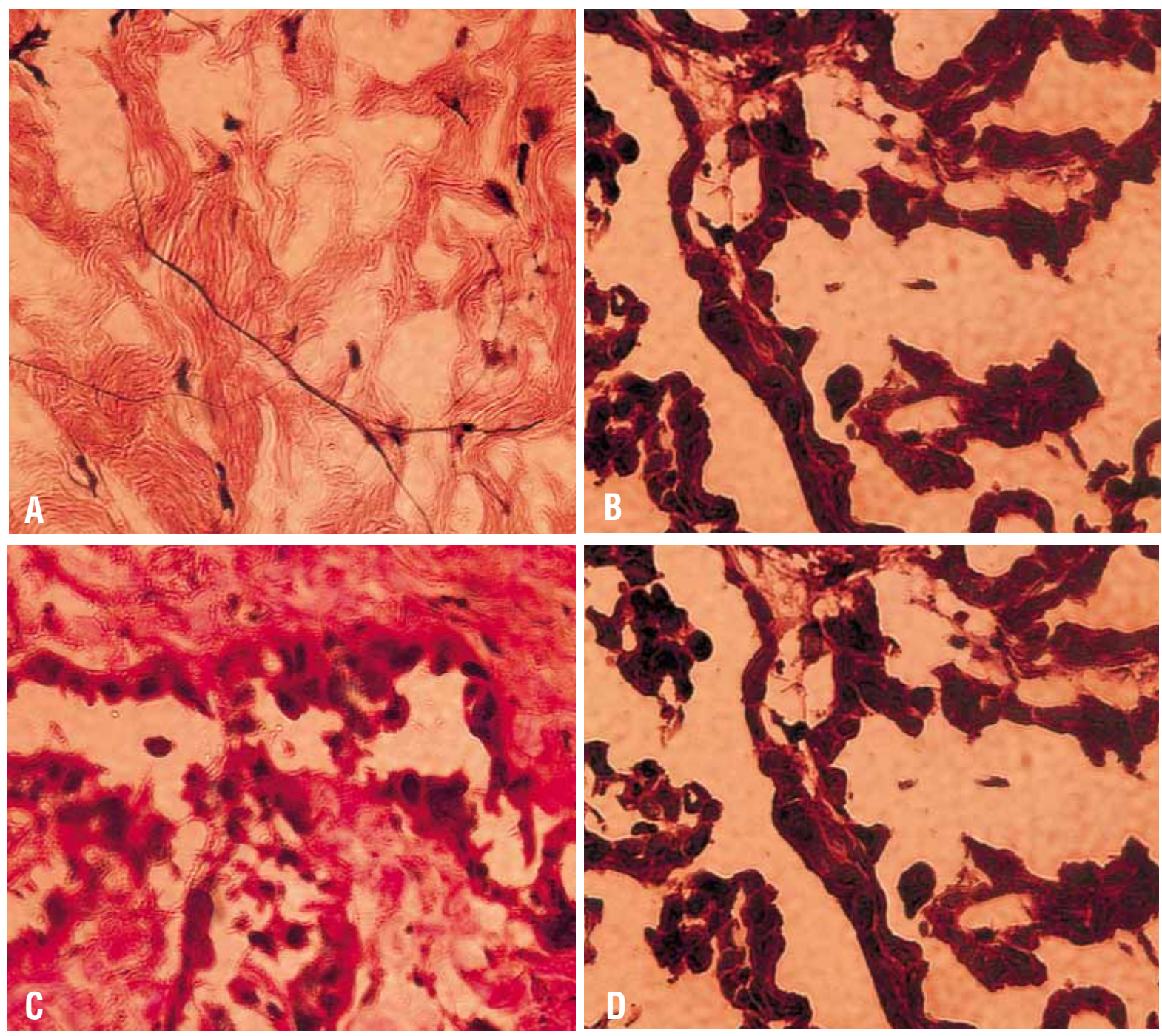

Fig 4. Immunoprecipitation with MOv 18 and Mov19 antibody on frozen section of normal pleura (A) and mesothelioma (B). Note the localization of the antibody in the membrane and cytoplasm of the mesothelioma tumor cells. The staining in adenocarcinoma of the lung tumor cells is positive $(\mathbf{C})$ and in squamous carcinoma of the lung is negative (D).

Using a nonselective method, we identified a $320 \mathrm{bp}$ mesothelioma cDNA tag that is expressed at a high level in mesothelioma compared with normal tissues that contain pleural mesothelial cells, pleura, and lung. This cDNA tag has a high homology to the $\alpha$ folate receptor cDNA. In fact, it is identical with the $117 \mathrm{bp}$ of the cDNA in the $3^{\prime}$ end of the coding sequence and highly homologous to the $3^{\prime}$ untranslated region. This gene tag is activated in 45 of 60 mesothelioma tissues studied, regardless of histologic type. Furthermore, this gene tag hybridizes to a $1.3 \mathrm{~kb}$ band in Northern blot, and this band is activated in mesothelioma. In addition, results of immunohistochemistry experiments performed with two anti- $\alpha$ folate receptor antibodies verify that the folate receptor is present in mesothelioma tumor cells at a higher level than in normal pleura and lung cells. Our results support the conclusion that the $\alpha$ folate receptor gene is highly expressed at both the RNA and protein levels in the majority of mesothelioma tissues that we have tested. To the best of our knowledge, this article is the first report of folate receptor overexpression in mesothelioma.

Folate receptor levels are elevated in a number of other cancers, most notably in ovarian carcinoma, pre- 
Table I. Quantitation of fluorescence in situ hybridization with the folate receptor probe in 61 mesothelioma tissues by histologic type

\begin{tabular}{lccccc}
\hline Intensity of hybridization & 1 (very low) & 2 (low) & 3 (moderate) & 4 (high) & $5($ very high) \\
\hline Epithelial & 0 & 4 & 5 & 10 & 9 \\
Mixed & 1 & 1 & 6 & 14 & 8 \\
Sarcomatoid & 0 & 0 & 0 & 2
\end{tabular}

sumably to avail the rapidly dividing tumor cells with folate, which is an essential compound used for purine and pyrimidine biosynthesis and eventually for DNA synthesis. Acquisition of folate is essential for the rapidly dividing cell, and its absence results in megaloblastosis and premature cell death. Folate can also be transported into the cell via the reduced folate carrier, which is a low-affinity, high-capacity transmembrane receptor different from the high affinity $\alpha$ folate receptor. ${ }^{17,20}$ The relative number of these two different receptors in the cell determines which one is more important in folate transport in a given tissue. Folate metabolism and transport have been exploited for many years in the pursuit of antitumor agents. Methotrexate is a chemotherapeutic drug that is a folate analog and is transported by both receptors. It acts by inhibiting dihydrofolate reductase..$^{20}$ Clearly, elevated expression of folate receptors may make mesotheliomas more susceptible to antifolate agents. It is interesting to point out that methotrexate is one of the few agents that has had a significant response (higher than 20\%) in mesothelioma. ${ }^{22}$ More recently, newer antifolate drugs such as the multitargeted antifolates have been shown to have significantly increased antimesothelioma activity in clinical trials. ${ }^{9}$ Our findings are certainly in keeping with the observed improved efficacy of antifolate drugs in mesothelioma. Our results should encourage a more aggressive focus on antifolates and more innovative antifolate targeting for the treatment of patients with malignant pleural mesothelioma. Analysis of the folate receptor levels before chemotherapy may be useful in selecting responders to antifolate drugs. Additional work is required to establish the mode of internalization of antifolate drugs and the importance of the folate receptor overexpression in mesothelioma.

We thank Mary Visciano for editorial assistance.

\section{REFERENCES}

1. Sugarbaker D, Norberto J, Bueno R. Current therapy for mesothelioma. Cancer Control 1997;4:326-34.

2. Kindler H. Mesothelioma. In: Vokes E, Golomb H, editors. Oncologic therapies. Berlin: Springer-Verlag; 1999. p. 635-51.

3. Bignon J, Brochard P, Pairon J-C. Mesothelioma: causes and fiber-related mechanisms. In: Aisner J, Arriagada R, Green M,
Martini N, Perry M, editors. Comprehensive textbook of thoracic oncology. Baltimore: Williams \& Wilkins; 1996. p. 735-56.

4. Aisner J. Diagnosis, staging, and natural history of pleural mesothelioma. In: Aisner J, Arriagada R, Green M, Martini N, Perry M, editors. Comprehensive textbook of thoracic oncology. Baltimore: Williams \& Wilkins; 1996. p. 799-885.

5. Ong S-T, Vogelsang N. Current therapeutic approaches to unresectable (primary and recurrent) disease. In: Aisner J, Arriagada R, Green M, Martini N, Perry M, editors. Comprehensive textbook of thoracic oncology. Baltimore: Williams \& Wilkins; 1996. p. 786-98.

6. Sugarbaker D, Liptay M. Therapeutic approaches in malignant mesothelioma. In: Aisner J, Arriagada R, Green M, Martini N, Perry M, editors. Comprehensive textbook of thoracic oncology. Baltimore: Williams \& Wilkins; 1996. p. 786-98.

7. Sugarbaker D, Flores R, Jaklitsch M. Resection margins, extrapleural nodal status, and cell type determine postoperative long-term survival in trimodality therapy of malignant pleural mesothelioma: results in 183 patients. J Thorac Cardiovasc Surg 1999;117:54-65.

8. Thodtmann R, Depenbrock H, Blatter J, Johnson R, van Oosterom A, Hanauske A-R. Preliminary results of a phase I study with MTA (LY231514) in combination with cisplatin in patients with solid tumors. Semin Oncol 1999;26(2 Suppl 6):89-93.

9. Thodtmann R, Depenbrock H, Dumez H, Blatter J, Johnson R, van Oosterom A, et al. Clinical and pharmacokinetic phase I study of multitargeted antifolate (LY231514) in combination with cisplatin. J Clin Oncol 1999;17:3009-16.

10. Baldini E, DeCamp M Jr, Katz M, Berman S, Swanson S, Mentzer $\mathrm{S}$, et al. Patterns of failure after trimodality therapy for malignant pleural mesothelioma. Ann Thorac Surg 1997;63:334-8.

11. Liang M, Pardee A. Differential display: a general protocol. Methods Mol Biol 1997;85:3-11.

12. Liang M, Pardee A. Differential display: a general protocol. Mol Biotechnol 1998;10:261-7.

13. Davis L, Dibner M, Battey J. Basic methods in molecular biology. New York: Elsevier Science; 1986. p. 129-52.

14. Mantovani L, Miotti S, Menard S, Canevari S, Raspagliesi F, Bottini $\mathrm{C}$, et al. Folate binding protein distribution in normal tissues and biological fluids from ovarian carcinoma patients as detected by the monoclonal antibiotics MOv128 and MOv19. Eur J Cancer 1994;30A:363-9.

15. Ratnam M, Marquardt H, Duhring J, Freisheim J. Homologous membrane folate binding proteins in human placenta: cloning and sequence of a cDNA. Biochemistry 1989;28:8249-54.

16. Wu M, Gunning W, Ratnam M. Expression of folate receptor type a in relation to cell type, malignancy, and differentiation in ovary, uterus, and cervix. Cancer Epidemiol Biomarkers Prevent 1999;8:775-82.

17. Antony A. Folate receptors. Annu Rev Nutr 1996;16:501-21.

18. Melani C, Figini M, Nicosia D, Luison E, Ramakrishna V, 
Casorati G, et al. Targeting of interleukin 2 to human ovarian carcinoma by fusion with a single-chain $\mathrm{Fv}$ of antifolate receptor antibody. Cancer Res 1998;58:4146-54.

19. Franklin WA, Waintraub M, Edwards B, Christensen K, Prendegast $\mathrm{P}$, Woods $\mathrm{J}$, et al. New anti-lung-cancer antibody cluster 12 reacts with human folate receptors present on adenocarcinoma. Int J Cancer Suppl 1994;8:89-95.

20. Sierra E, Goldman I. Recent advances in the understanding of the mechanism of membrane transport of folates and antifolates. Semin Oncol 1999;26:11-23.

21. Rodolfo J, Melani C, Zilocchi C, Cappetti B, Luison E, Arioli I, et al. IgG2a induced by interleukin (IL) 12-producing tumor cell vaccines but not IgG1 induced by IL-4 vaccine is associated with the eradication of experimental metastases. Exp Oncol 1998;58:5812-7.
22. Solheim O, Saeter G, Finnanger A, Stenwig A. High-dose methotrexate in the treatment of malignant mesothelioma of the pleura: a phase II study. Br J Cancer 1992;65:956-60.

\section{Discussion}

Dr Nasser K. Altorki (New York, NY). Dr Bueno, how do you know that you did not get nonspecific binding with your antibody? Did you preabsorb the antibody?

Dr Bueno. Yes, we preabsorbed to avoid nonspecific banding before incubation with the antibodies. We got the same results in the ovarian cancer-positive controls and negative results in the tissues that were known not to express it. 